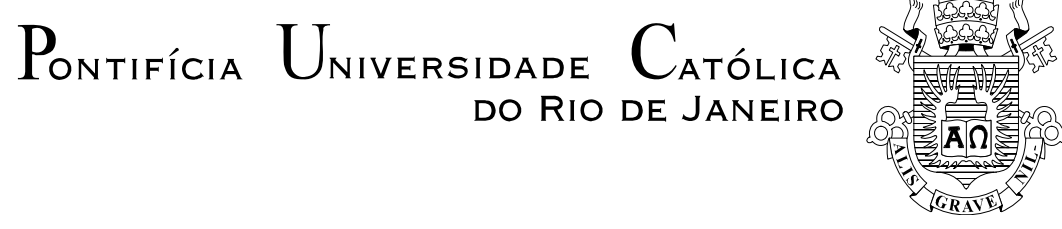

FLÁVIO ESTEVES SODRÉ

\title{
DA SUTILEZA DO MÍNIMO E DO DEVANEIO QUE O MOVE
}

\author{
Dissertação de Mestrado
}

Dissertação de Mestrado apresentada como requisito parcial para obtenção do grau de Mestre em Letras do Departamento de Letras da PUC-Rio como parte dos requisitos parciais para obtenção do título de Mestre em Letras.

Orientadora: Profa. Ana Paula Veiga Kiffer

Rio de Janeiro

Abril de 2008 


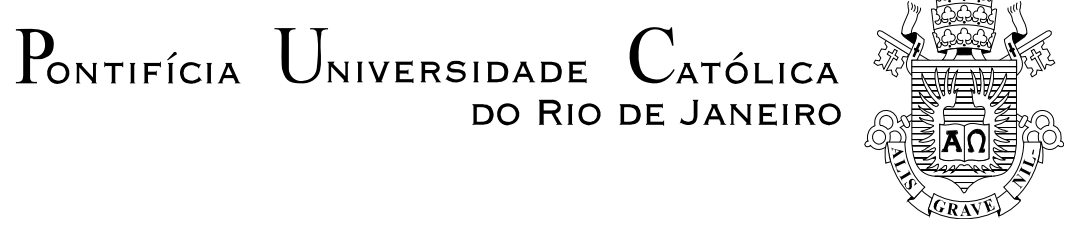

FLÁVIO ESTEVES SODRÉ

\section{DA SUTILEZA DO MÍNIMO E DO DEVANEIO QUE O MOVE}

\section{Dissertação de Mestrado}

Dissertação apresentada como requisito parcial para obtenção do grau de Mestre pelo programa de PósGraduação em Letras do Departamento de Letras do Centro de Teologia e Ciências de Teologia e Ciências Humanas da PUC-Rio. Aprovada pela Comissão Examinadora abaixo assinada.

Profa. Ana Paula Veiga Kiffer
Orientadora
Departamento de Letras - PUC-Rio

Prof. Paulo Fernando Henriques Britto Departamento de Letras - PUC-Rio

Prof. Valter Sinder

Departamento de Sociologia - PUC-Rio

Prof. Paulo Fernando Carneiro de Andrade

Coordenador Setorial do Centro de Teologia

e Ciências Humanas - PUC-Rio

Rio de Janeiro, de de 
Todos os direitos reservados. É proibida a reprodução total ou parcial do trabalho sem autorização da universidade, do autor e da orientadora.

Flávio Esteves Sodré

Graduou-se em Ciências Sociais pela PUC-Rio em 2004.

Ficha Catalográfica

Sodré, Flávio Esteves

Da sutileza do mínimo e do devaneio que o move / Flávio Esteves Sodré ; orientadora: Ana Paula Veiga Kiffer. $-2008$.

88 f. ; $30 \mathrm{~cm}$

Dissertação (Mestrado em Letras) - Pontifícia Universidade Católica do Rio de Janeiro, Rio de Janeiro, 2008.

Inclui bibliografia

1. Letras - Teses. 2. Mínimo. 3. Digressão. 4. Miniatura. 5. Devaneio. 6. Imaginação. 7. Tempo. 8. Silêncio. I. Kiffer, Ana Paula Veiga. II. Pontifícia Universidade Católica do Rio de Janeiro. Departamento de Letras. III. Título. 


\section{Agradecimentos}

Como deixar de agradecer aos que mais me ajudaram durante este processo? Fica aqui, pois, uma nota de carinho à Ana Paula, que me orientou sempre com muita confiança; sua crítica severa nunca tolheu a liberdade de meus devaneios. Tampouco posso me esquecer do Valter e da Santuza: se dispuseram amavelmente a escrever as cartas de recomendação que me ajudaram a iniciar o Mestrado que agora concluo. Devem ter sido bonitas, e bem sei que serviram para lançar a "pedra fundamental" desta jornada. Fundamentais foram também Lucía, que tantas vezes foi dormir sozinha enquanto eu via as noites em claro; nossa família peruana (são muitos, impossível nomear!); Carlos, Rafael, Roger, Beto, Erica e Diego, pela iniciação teatral e pela explosão da sensibilidade de meu olhar para o sutil. E ao João Carlos, que me ensinou o óbvio de que em música se deve também tocar a pausa. Agradeço ainda ao "pessoal do Rio" - Fred, João, Fernanda, Tati, Kata e Helena, porque, se bem me lembro, foram eles quem me convenceram a começar tudo isso. E, é claro, aos meus pais e irmãos, pelo incentivo constante. Por último, mas não menos importante, ao $\mathrm{CNPq}$, que tanto me ajudou com sua bolsa de estudo. 


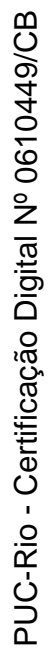

Para Tito, que cresça devagar e aproveite em dobro todo o tempo que tem. 


\section{Resumo}

Sodré, Flávio Esteves; Kiffer, Ana Paula Veiga (Orientadora). Da sutileza do mínimo e do devaneio que o move. Rio de Janeiro, 2008. 88p. Dissertação de Mestrado - Departamento de Letras, Pontifícia Universidade Católica do Rio de Janeiro.

Esta dissertação pretende desenvolver uma reflexão sobre o que, de início, foi chamado de movimento mínimo. Desejando estabelecer um diálogo entre a música - especificamente com algumas composições de John Cage - e autores como Bachelard, Bergson, Beckett, Buzzati, Borges, Barthes, Boulez, entre outros, o texto vai à procura das mais sutis forças de movimentação presentes em aparentes "estados de imobilidade", aqui apresentados como o "silêncio", o "tempo de espera", o "devaneio criador", o "jardim das miniaturas" etc. Essas figuras de representação desejam mostrar ao leitor que conceitos geralmente conectados a uma lacuna, uma falta e uma ausência de valor encontram neste "defeito" seu maior predicado, transformando-se em potência ativa de criação.

\section{Palavras-chave}

Mínimo, digressão, miniatura, devaneio, imaginação, tempo, silêncio. 


\section{Resumen}

Sodré, Flávio Esteves; Kiffer, Ana Paula Veiga (Orientadora). De la sutileza del mínimo y el devaneo que lo mueve. Rio de Janeiro, 2008. 88p. Dissertação de Mestrado - Departamento de Letras, Pontifícia Universidade Católica do Rio de Janeiro.

Esta disertación pretende desarrollar una reflexión acerca de lo que fue llamado movimiento mínimo. Intentando establecer un dialogo entre la música específicamente con algunas composiciones de John Cage - y autores como Bachelard, Bergson, Beckett, Buzzati, Borges, Barthes, Boulez, entre otros, el texto procura las más sutiles fuerzas de movimiento presentes en aparentes "estados de inmovilidad", aquí presentados como el "silencio", el "tiempo de espera", el "devaneo criador" etc. Esas figuras de representación desean mostrar para el lector que conceptos generalmente conectados a una laguna, una falta y a una ausencia de valor pueden encontrar en este "defecto" su más grande predicado, transformándose en potencia activa de creación.

\section{Palabras-Ilave}

Mínimo, digresión, miniatura, devaneo, imaginación, tiempo, silencio. 


\section{Sumário}

$\begin{array}{lr}\text { Anteriormente } & 9\end{array}$

$\begin{array}{ll}\text { Não é aqui que começa } & 17\end{array}$

$\begin{array}{ll}\text { Panorama do não } & 21\end{array}$

4'33'’ 32

mise en abîme 36

O Jardim das Miniaturas $\quad 49$

Tempo de Espera

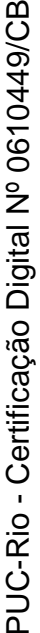

Thomas Mann e a bildung da espera $\quad 59$

$\begin{array}{ll}\text { Buzzati e a Imaginação tartárea } & 70\end{array}$

$\begin{array}{ll}\text { À espera da fera } & 76\end{array}$

$\begin{array}{ll}\text { Nada a fazer } & 78\end{array}$

Referências bibliográficas $\quad 86$ 